\title{
Age-Related Modifications in Circulating IL-15 Levels in Humans
}

\author{
Sebastiano Gangemi, ${ }^{1}$ Giorgio Basile,${ }^{2}$ Daniela Monti, ${ }^{3}$ Rosaria Alba Merendino, ${ }^{1}$ Giuseppe \\ Di Pasquale, ${ }^{4}$ Ursula Bisignano, ${ }^{4}$ Vittorio Nicita-Mauro, ${ }^{2}$ and Claudio Franceschi ${ }^{5}$ \\ ${ }^{1}$ Department of Human Pathology, School of Allergy and Clinical Immunology, University of Messina, Messina 98125, Italy \\ ${ }^{2}$ Department of Internal Medicine, Division of Geriatric Medicine, University of Messina, Messina 98125, Italy \\ ${ }^{3}$ Department of Experimental Oncological Pathology, University of Florence, Tuscany 50134, Italy \\ ${ }^{4}$ Department of Internal Medicine, University of Messina, Messina 98125, Italy \\ ${ }^{5}$ Interdepartmental Center "L. Galvani" for Integrated Studies on Bioinformatics, \\ Biophysics, and Biocomplexity, University of Bologna, Bologna 40100, Italy
}

Received 25 February 2005; accepted 18 April 2005

\begin{abstract}
Aging is associated to a progressive establishing of a chronic inflammatory state linked to a continuous long exposure to antigens. Since IL-15 stimulates the proliferation of memory T cells and the immunosenescence is characterized by accumulation of memory $\mathrm{T}$ cells and exhaustion of naive T cells, we analyzed IL-15 levels in sera from 30 ultralongeval subjects with respect to those from young and old adults. IL-15 levels were assayed by immunoenzymatic methods. Ultralongeval subjects displayed significantly higher IL-15 levels with respect to both young and old controls. No statistical difference was found between old and young controls. These findings may explain, at least in part, the characteristic increase of memory cells in immunosenescence and the capacity of the immune system of centenarians to defend itself from infections through immune-inflammatory responses.
\end{abstract}

\section{INTRODUCTION}

Accumulating evidences strongly suggest that aging is associated to a progressive establishing of a chronic inflammatory state characterized by the release of several proinflammatory cytokines, linked to a continuous long exposure to antigens, which appears to be under genetic control [1].

The beneficial effects of the immune system, devoted to the neutralization of harmful agents early in life, become detrimental and could explain the pathogenesis of the age-related diseases, such as atherosclerosis, diabetes, neurodegeneration [1].

It has been demonstrated that all the components of immune system show age-related dysregulation, and numerous studies have been performed in order to investigate the cytokine network in elderly people with conflicting results.

Interleukin (IL)-15, a monocyte- and epithelial-cellderived cytokine, produced in response to environmental stimuli and infectious agents, shares a variety of biological functions including stimulation and maintenance of cel-

Correspondence and reprint requests to Sebastiano Gangemi, Department of Human Pathology, School of Allergy and Clinical Immunology, University of Messina, Via Centonze 200, is. 98, Messina 98123, Italy; paola.minciullo@tin.it lular immune response [2]. This cytokine, similar to IL-2 in receptor specificity and biological functions (the specificity for IL-15 is provided by unique private $\alpha$-chain receptors), is important for the growth and differentiation of $\mathrm{B}$ and $\mathrm{T}$ lymphocytes, NK cells, macrophages, and monocytes. The heterotrimeric IL-15 receptor (IL-15R) consists of IL-15R $\alpha$, which uniquely binds IL-15, as well as IL-2R $\beta$ and $\gamma_{c}$, which mediate signal transduction events after IL-2 and IL-15 binding [2].

IL-15 is characterized by a pleiotropic activity that results in immunoregulatory cross-talk between natural and specific immune cells [2].

Moreover, IL-15 induces the differentiation of functional $\mathrm{CD} 6^{+} \mathrm{NK}$ cells from CD34 haematopoietic cells, allowing innate immune defense against viruses, fungi, bacteria, and protozoa [2].

In order to investigate whether this important cytokine is influenced by aging, we analyzed IL-15 levels in sera from ultralongeval subjects ( $>95$ years), elderly subjects (60-89 years), and adults aged less than 60 years.

We investigated 30 ultralongeval subjects (26 female, 4 male; 12 aged 95-99 years, and 18 ultracentenarians).

All ultralongeval subjects were living at home independently and able to carry out usual day activity on their own or with little help. They were in good health, no smokers, without past or present history of myocardial infarction, acute cerebrovascular events, diabetes, cancer, 


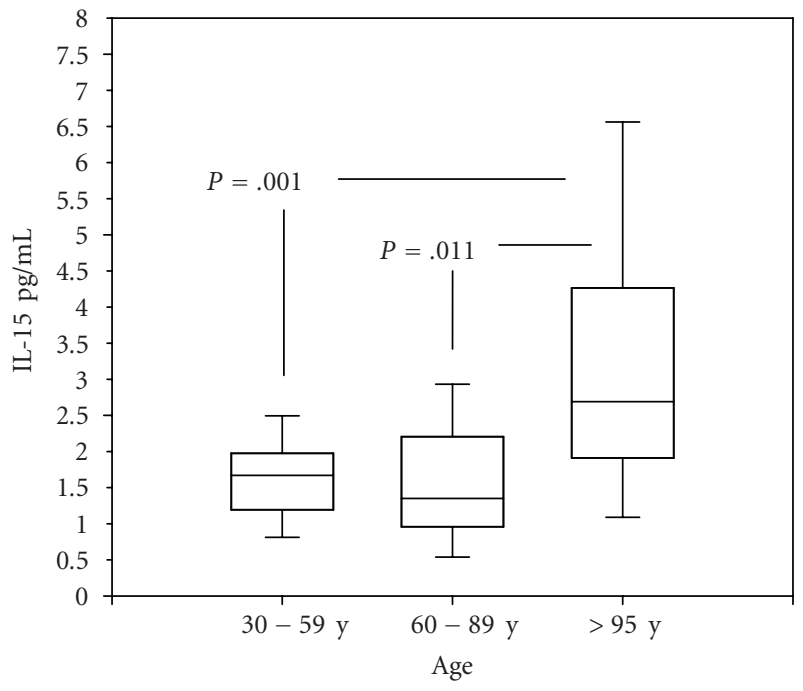

FIgUre 1. Age-related changes in serum IL-15 levels. Box blot illustrates median of IL-15 in groups of individuals with different ages.

or nephropathy. 42 healthy sex-matched individuals were also recruited as controls and divided into two groups: group $\mathrm{A}(n=21$, age range $60-89$ years) and group $\mathrm{B}$ $(n=21$, age range $30-59$ years). All subjects gave a written informed consent to participate in the study.

A 10-mL blood sample was collected from the antecubital vein, allowed to clot at room temperature for 2 hours, separate by centrifugation at 200-xg for 15 minutes in a 4235 A centrifuge (ALC Int SrL, Milan, Italy), and stored at $-80^{\circ} \mathrm{C}$ until use.

IL-15 levels were assayed by immunoenzymatic methods (Quantikine Human IL-15, ELISA-kits, R\&D System, SPACE Import-Export, Milan, Italy). The minimum detectable concentration of IL-15 is $2 \mathrm{pg} / \mathrm{mL}$.

Differences in IL-15 levels were assessed by the Wilcoxon Signed Rank Test. Data are expressed as mean \pm standard deviation (SD). A $P$ value $<.05$ was considered significant.

All data were analyzed using the Stat View SE program (Abacus, Berkeley, Calif, USA).

IL-15 serum levels were significantly higher in ultralongeval subjects with respect to both old and young controls $(3.05 \pm 1.41$ versus $1.94 \pm 1.32 \mathrm{pg} / \mathrm{mL}, P=.011$, and versus $1.73 \pm 0.50 \mathrm{pg} / \mathrm{mL}, P=.001$, respectively) (Figure 1).

No statistical difference was found between old and young controls.

First data of our study show that there are not statistically significant differences between old and young controls. These results are in agreement with those reported by Tortorella et al, although in different experimental conditions. In fact, after a 24-hour PHA stimulation, PBMC from aged donors produced IL-15 at levels similar to those found in the young [3].
But in this paper, Tortorella showed also that IL-15 modulation on PHA-induced IFN-gamma production by PBMC determined a sixfold increase in cytokine values in the young volunteers, but only a 1.7 -fold increase in the group of aged subjects. Furthermore, IL-15 added to PBMC cultures enhanced the PHA-triggered T-cell proliferative response only in young individuals, being ineffective in the old counterparts [3].

This impairment of IL-15 signaling in the elderly subjects may be related to a reduction in IL-15 receptors or in the activity of kinases involved in cytokine-triggered cell signaling [3].

Centenarians can be considered as a useful model for the study of the biological basis of healthy aging.

Aging is characterized by a chronic inflammatory status also called "inflammaging," in which the upregulation of antistress responses is the consequence of the ability of the body to adapt to and counteract the effects of stressors, which causes the accumulation of molecular and cellular scars [1]. In particular, centenarians display increased circulating levels of inflammation markers, including IL-6, ICAM-1, and IL-18 [4].

Moreover, continuous exposure to antigens causes a lifelong antigenic stress responsible, together with the involution of the thymus, for the accumulation of memory/effector $\mathrm{T}$ cells and the exhaustion of naive $\mathrm{T}$ cells [1].

IL-15 stimulates the proliferation of human memory $\left(\mathrm{CD} 45 \mathrm{RO}^{+}\right) \mathrm{CD} 4, \mathrm{CD} 8$, and naive $(\mathrm{CD} 45 \mathrm{RO}) \mathrm{CD}^{+}$ human $\mathrm{T}$ cells in vitro, while having no effect on naive CD4 T lymphocytes, consistent with IL-2/15R $\beta$ expression [2].

Recently, Burkett et al showed that expression of the high-affinity receptor for IL-15 (IL-15R $\alpha$ on T cells is dispensable for the generation or survival of memory $\mathrm{CD}^{+}$ T cells, whereas IL-15R $\alpha$ expression on other cells is critical for supporting memory CD8 ${ }^{+} \mathrm{T}$ cells [5]).

These findings demonstrate that IL- $15 \mathrm{R} \alpha$ supports memory $\mathrm{CD}^{+} \mathrm{T}$ cells entirely through non-cellautonomous mechanisms, probably related to the ability of IL- $15 \mathrm{R} \alpha$ to present IL-15 in trans to IL- $15 \mathrm{R} \beta / \gamma_{c}$ lowaffinity receptors.

In the present study, we demonstrated, for the first time, that ultralongeval subjects displayed significantly higher circulating IL-15 compared to each of the two agecontrol populations.

Then, our findings may explain, at least in part, the increase of memory cells characteristic of elderly subjects [1].

On the other hand, IL-15 induces the differentiation of functional CD56 ${ }^{+} \mathrm{NK}$ cells from CD34 haematopoietic cells and $\mathrm{CD}^{2} 6^{+} \mathrm{NK}$ cells have a key role in innate immune defense against viruses, fungi, bacteria, and protozoa [2].

So, this demonstration of the strong increase of IL-15 in ultralongeval subjects may contribute to a better understanding of the mechanisms at the basis of the well-known 
capacity of the immune system of centenarians to defend itself from infections through efficient immuneinflammatory responses that may be crucial for longevity.

\section{ACKNOWLEDGMENT}

This work was supported in part by a grant from the University of Messina Medical School (ex 60\%), Italy.

\section{REFERENCES}

[1] De Martinis M, Franceschi C, Monti D, Ginaldi L. Inflamm-ageing and lifelong antigenic load as major determinants of ageing rate and longevity. FEBS Lett. 2005;579(10):2035-2039.

[2] Fehniger TA, Caligiuri MA. Interleukin 15: biology and relevance to human disease. Blood. 2001;97(1):14-32.

[3] Tortorella C, Pisconti A, Piazzolla G, Antonaci S. APC-dependent impairment of $\mathrm{T}$ cell proliferation in aging: role of CD28- and IL-12/IL-15-mediated signaling. Mech Ageing Dev. 2002;123(10):1389-1402.

[4] Gangemi S, Basile G, Merendino RA, et al. Increased circulating Interleukin-18 levels in centenarians with no signs of vascular disease: another paradox of longevity? Exp Gerontol. 2003;38(6):669-672.

[5] Burkett PR, Koka R, Chien M, et al. IL-15R alpha expression on $\mathrm{CD}^{+} \mathrm{T}$ cells is dispensable for $\mathrm{T}$ cell memory. Proc Natl Acad Sci U S A. 2003;100(8):47244729. 


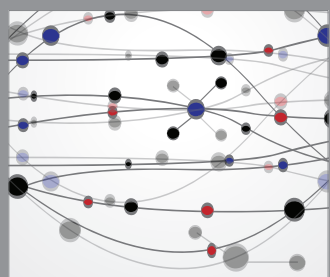

The Scientific World Journal
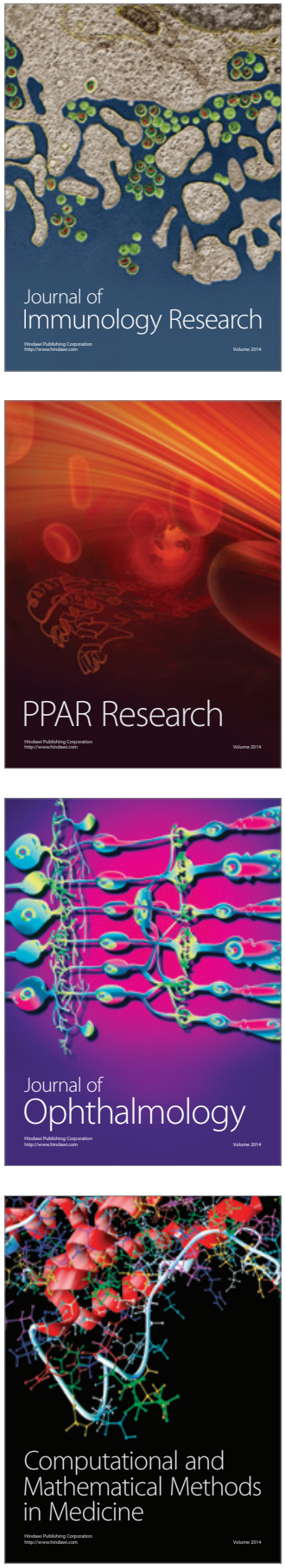

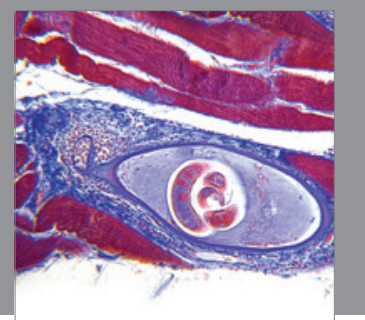

Gastroenterology

Research and Practice
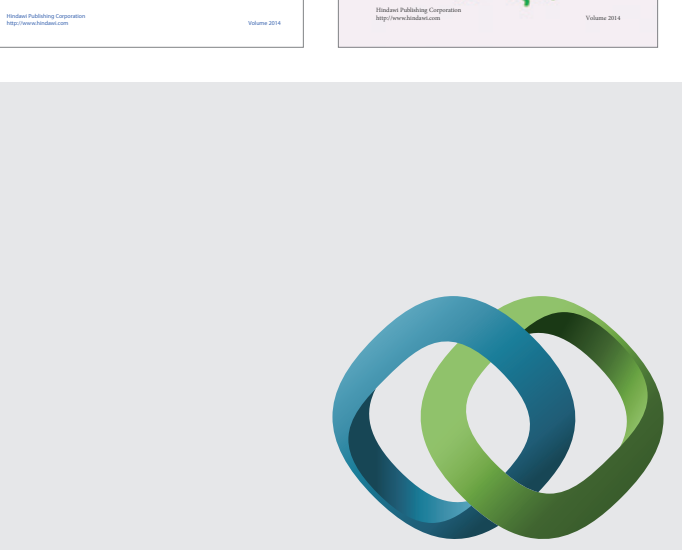

\section{Hindawi}

Submit your manuscripts at

http://www.hindawi.com
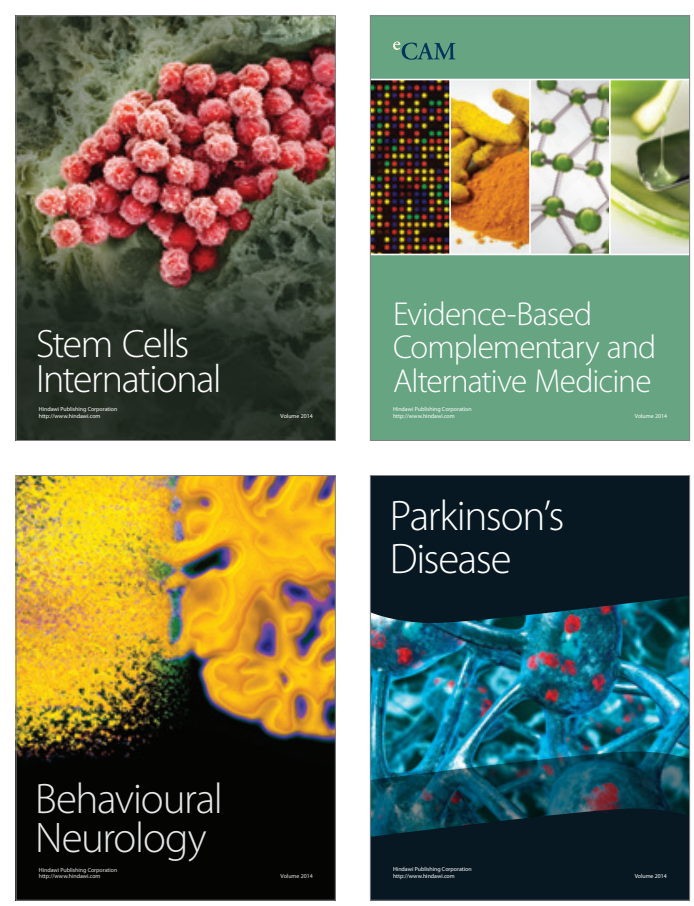

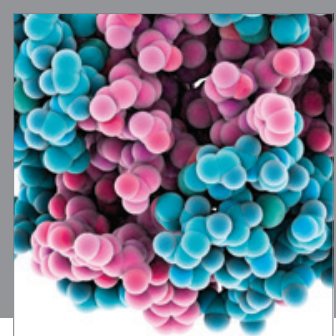

Journal of
Diabetes Research

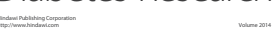

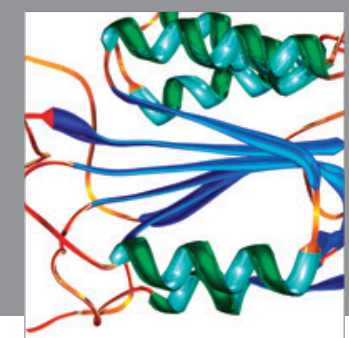

Disease Markers
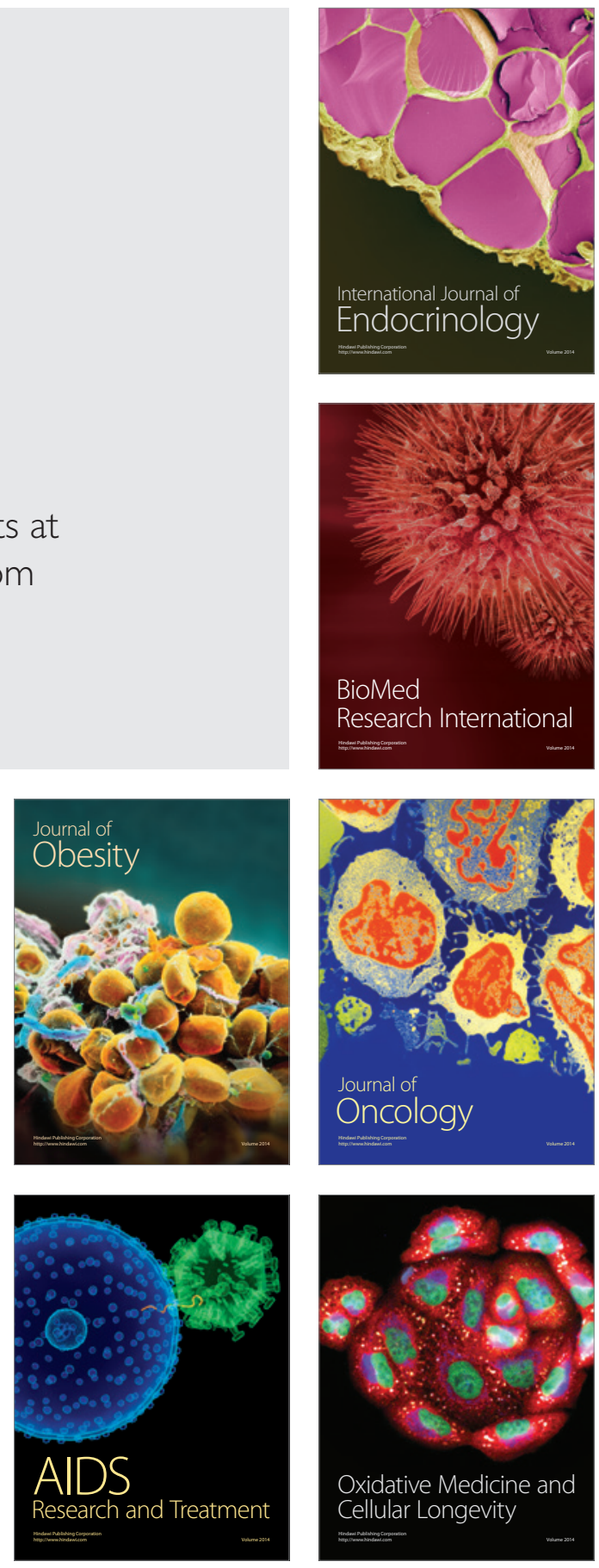